\title{
Monitoring Deterioration in a Catchment's Sewerage System
}

\author{
Ross Sparks $^{1, *}$ and Andrew Kasmarik ${ }^{2}$ \\ ${ }^{1}$ CSIRO Mathematics, Informatics and Statistics, Australia \\ ${ }^{2}$ Milroy Jayaveerasingam, and Jovan Titus, Asset Planning, Sydney Water, Australia
}

\begin{abstract}
Groundwater seepage through cracks in the sewerage pipeline is a major maintenance issue in most cities' sewer networks. The more the sewer pipes crack - and the wider these cracks are - the worse the rainfall seepage problem becomes.

The total volume of rainwater seepage into the sewer pipes for a catchment is correlated with deterioration and can therefore be used to estimate the rate of deterioration. This paper describes a monitoring system that can be used to identify significant trends in sewer deterioration.
\end{abstract}

Effective monitoring by asset managers can highlight the need for early maintenance such as removing tree roots from pipe cracks and patching the cracks.

Keywords: Bias, degradation, estimation, prediction, seepage, statistical process control.

\section{INTRODUCTION}

Maintaining the pipelines in a sewerage system has become a major asset management challenge for most cities. Ageing pipes need constant repair and maintenance as cracks appear and tree roots exploit these cracks for nutrients.

The "uncertainties regarding long-term performance and the lack of indicators for system failure" have been indicated as major barriers to meet maintenance responsibilities [1]. A monitoring system that can offer early warning of significant deterioration can assist asset managers in targeting the maintenance effort and thus help prevent system failures. It can also offer a way of estimating the value of the maintenance effort in terms of reduced infiltration (seepage). Early intervention may also reduce overall maintenance costs.

Several authors have looked at assessment of sewer leakage using exfiltration [2,3]. In this paper, deterioration in a catchment system in Sydney Australia is measured by the amount of rainfall that gets into the sewerage system. A common rainfall event is used across all years to estimate seepage with the aim of tracking deterioration trends over a number of years.

Some studies have examined the factors influencing deterioration in pipes and have used closed-circuit television (CCTV) to observe infiltration and determine the severity of defects [4,5]. However, the sewer network in Sydney does not have the benefit of CCTV cameras in the sewer and so this approach was not possible for the application in this

*Address correspondence to this author at the CSIRO Mathematics, Informatics and Statistics, Australia; Tel: +61 2 93253262; Fax: +61 2 93253200; E-mail: Ross.Sparks@csiro.au paper. Sewer deterioration is estimated here by accounting for additional infiltration during small rainfall events generally caused by the presence of cracks in the pipes. This paper takes the infiltration estimation work of Lutz [6] one step closer to a sustainable system for monitoring unusual deterioration in a sewer catchment.

Tsitsifli et al. [7] focused on monitoring sewer pipeline deterioration by estimating the likelihood of the next pipe failure, where water leakage is regarded as one of the failures. Their focus was drinking water where leaks are a loss of a resource. In our application, leakage is only a loss if the overflow is sufficiently large to cause an adverse environmental impact. We therefore try to measure deterioration in a way that may avoid catastrophic failures. Early warning allows for the appropriate maintenance effort, like removing tree roots from the cracks in pipes and patching the cracks. This effort reduces the number of overflows - and thus the risk to the environment - because less rainfall water seeps into the sewerage pipes.

\section{METHOD}

Seepage can be estimated at the outflow point of a catchment. If we had perfect models that fitted both the dry weather flows in sewerage pipes and the wet weather flows for rainfall events - and there were no overflow points in the catchment - then the total amount of rainfall seeping into the sewerage system for the catchment would be the integration of the difference between the model-predicted wet weather flows and the model-predicted dry weather flows for the duration of a rainfall event.

Fig. (1) demonstrates the difference for one time period in this integration. It presents a plan view of a sewer pipe at 


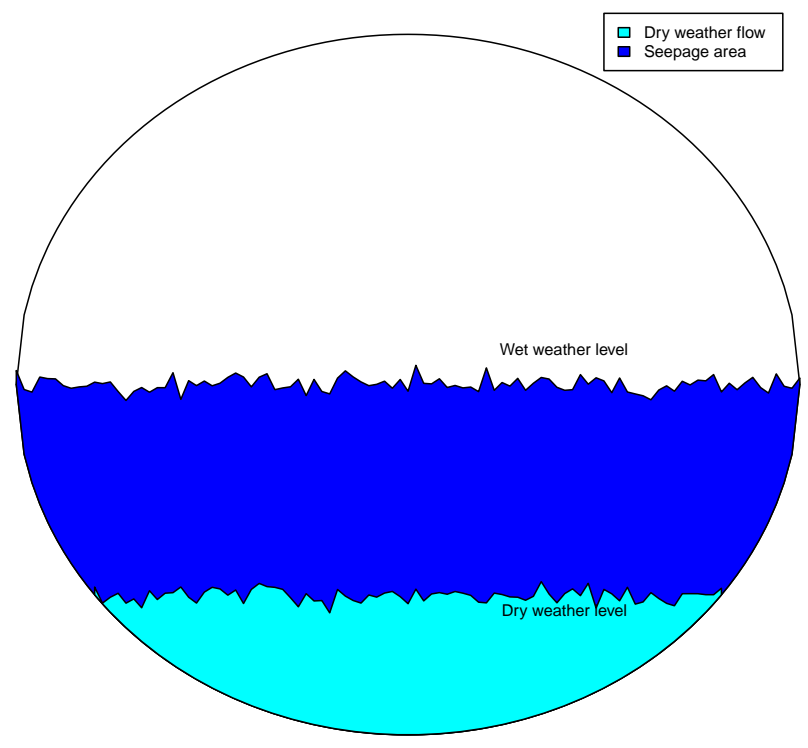

Fig. (1). A plan view of the seepage estimation process at one time point.

the end of a catchment for a single point in time during two weather states. The two weather states considered in this figure are the dry weather flows at a particular date and time, and the wet weather event flows at the same date and time. The difference in area between the levels in the pipe of the wet weather flows and the dry weather flows (dark shaded area) is proportional to the volume of seepage for that particular point in time.

If this area is integrated across time for the duration of the rainfall event's influence we can then estimate the total seepage for the rainfall event (provided there were no overflows upstream of this point in the sewer during the rainfall event). Hypothetically, if this identical rainfall event occurred at the same time, day-of-the-week and date of the year for every year (assuming this were possible), we could use this to estimate the total seepage for each year. This would provide the means of assessing to what extent the sewer catchment is deteriorating by assessing the increase in estimated total seepage volume for this same rainfall event over time (in years). Using the same rainfall event, day-of-theweek and time of day makes certain that our comparison process compares like with like - the only difference being the increased amount of seepage attributable to pipe deterioration.

A brief outline of the process in steps is as follows:

1. Find rainfall events without overflows. This is important because many overflow points have no instrumentation for measuring overflow volumes.

2. Fit hydrological/empirical models to the measured flows. Check that the models do not suffer any temporal biases (particularly during the rainfall event) and magnitude biases (e.g. biases for higher flows). Compare competing models and select the model with the smallest mean square error of prediction.

3. For each year, use hydrological/empirical models to estimate what the flow would have been for dry weather flows, for the same date, day-of-the-week, time-of-theday as the rainfall event used to compare infiltration. Carry this out for the wet weather event's entire duration of influence on flows.

4. For each year, use hydrological/empirical models to estimate the flows that would have occurred if this same wet weather event was repeated each year at the exact same time and day of the year, that is, estimate the flows throughout the duration of this wet weather event.

5. For each year in the assessment period, estimate the total seepage for the duration of the wet weather event by subtracting the integral of the dry weather estimated flows from the integral of the wet weather event estimated flows.

6. Use statistical process control methods across years to assess whether the seepage volume increases significantly with each increasing year during the assessment period. This increase would flag any significance increase in the deterioration of the sewer in the catchment. Early response to significant deterioration is thought to save maintenance costs by repairing the damage before it gets too bad.

For effective monitoring it is essential that we have unbiased estimates of seepage. It is not possible to obtain unbiased seepage estimates when there are overflows because the overflows cannot be measured. Therefore one of the challenges in monitoring seepage is to avoid rainfall events with overflows. If overflows are ignored, the unknown overflow can cause serious biases in our seepage estimates and thus devalue the monitoring effort.

The data sources are gauged measurements of flow, level and velocity at several locations in the catchment and more importantantly at the exit of the catchment. Data are also sourced from hydrological/statisical models used to estimate level, velocity and flows during hypothetical rainfall events and during dry weather.

\section{ILLUSTRATIVE APPLICATION}

The goal of the application was to reliably estimate the total rainfall seepage into the sewerage pipes in a specific catchment within the Sydney Metropolitan area - the Castle Hill catchment - and to monitor it over common rainfall events across several years. The estimate was taken at the outflow point of the catchment.

Castle Hill is $62 \%$ residential, $2 \%$ commercial, $12 \%$ industrial and open space/ parkland takes up about $15 \%$ of the area. Population is about 30,000. Castle Hill has a sanitary sewer that leaks and allows stormwater and ground water infiltration. The sewer design has not made allowances for wet weather events or growth in the population. About $90 \%$ of the pipes are $150 \mathrm{~mm}$ in diameter. This means their actual capacity is often much higher than the nominal design amount. The sewerage catchment area is 1,219 ha. Total length of sewers within the Castle Hill catchment is $193,180 \mathrm{~m}$. The number of designed overflow structures is 20 in 10 years and there were 20 spillages from manholes in 10 years. Fourteen sewer gauges are used in sewer model calibration. There 
are no incoming sewer flows to Castle Hill catchment. provides details of the Castle Hill sewer catchment, including the overflow and spill points (at manholes).

\subsection{Identifying Rainfall Events Without Overflows}

Every catchment has ungauged overflow points and so unbiased seepage estimates were not possible for all rainfall events. The challenge was therefore to find rainfall events with no overflows, and then monitor seepage for these events over time.

The level of flows in sewer pipes in the catchment is measured at several locations and this provided us with some information on when overflows were likely. However, if rainfall is heavy and localised then overflows can still occur by surges in local seepage. There was a need, therefore, to derive a method of estimating when overflows may occur. We wanted to know how much rain needs to fall and for how long after this before an overflow is likely. The strategy to find rainfall events without overflows is two fold:

1. Reduce the risk of overflows by identifying rainfall events that occur during periods with low dry weather flows.

2. Find a range of rainfall events that do not lead to overflows, and include several of these of varying durations and magnitudes in the seepage evaluation to check consistency in the seepage trends across different size events.

We started by classifying a dry weather state. This was done by excluding flow data within 12 hours of the ends of a rainfall event. Although this may leave periods where the soil is saturated and some seepage occurs, this will be swamped by many dry weather periods. Note that the evaluation period was during a major drought (2003 to 2009). A linear model was fitted using level as the response variable and harmonics for time-of-the-day (denoted hour) and weekday factor (denoted $w d$ ) as explanatory variables to the 'dry weather' data.

The fitted model explained $78 \%$ of the variation in the dry weather flow levels, and if time (day number) were included as an explanatory variable as well, then the model would explain $82 \%$ of the variation. If we include public holidays in the model, then the model fit would further improve. Obvious outliers were ignored (i.e. not excluded) because they did not influence the model fit much, and we were only interested in identifying when the dry weather flows were low.

This model established that peak dry weather flows occur between $10 \mathrm{pm}$ to about $6 \mathrm{am}$ and from $1 \mathrm{pm}$ to $4 \mathrm{pm}$ during the day (see Fig. (2) - note a weekend influence).

Next we considered what rainfall events would cause overflows. To minimise the risk we examined overflows at peak dry weather flows. That is, we examined the level in the sewerage pipes at gauged locations during rainfall events at peak dry weather flowing times of 7 to 10 am and 5 to $8 \mathrm{pm}$. Change point detection technologies were used to identify rainfall events with overflows [11].

The approach used to determine rainfall events with no overflows is as follows:

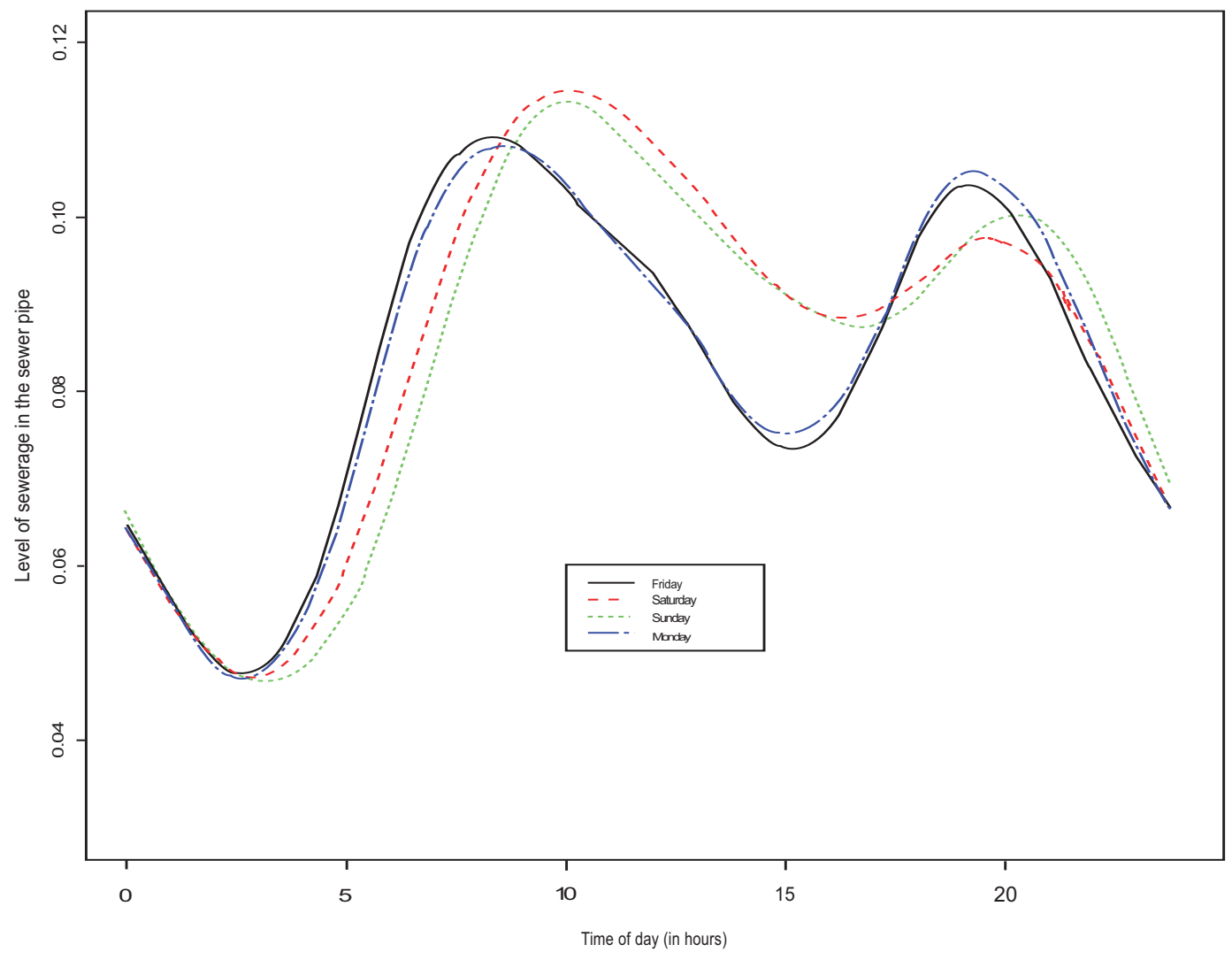

Fig. (2). Times series of model-fitted level of sewerage (in meters) versus time of the day. 
- Establish all rainfall events and let $X_{s}$ be the rainfall at the start (first $15 \mathrm{~min}$ ).

- Rank these rainfall values $0<x_{1, s}<x_{2, s}<\ldots<x_{N, s}$ and let the corresponding levels be $0<y_{1, s}<y_{2, s}<\ldots<y_{N, s}$.

- Start by considering only rainfall events with $0<x_{1, s}<x_{2, s}<\ldots<x_{n, s} \leq 1 m m$ and fit the model $y_{i, s}=\beta_{i, j, n}+\alpha_{n} x_{i, s}+e_{i n}$ where $\beta_{i, j, n}$ is the level for the dry weather flows at the different times of the day and $\alpha_{i n}$ is the rate of increase in level with rain and $e_{i n}$ is the random error term with mean zero and constant variance. Calculate the mean square error for this fitted model, denote this mse $_{n}$.

- Next considering only rainfall with $0<x_{1, s}<x_{2, s}<\ldots<x_{n, s} \leq x_{n+1, s}$ and fit the model $y_{i, s}=\beta_{i, j, n+j}+\alpha_{n+1} x_{i, s}+e_{i n+1}$. Calculate the mean square error mse $_{n+1}$.

- Recursively consider only rainfall events with $0<x_{1, s}<x_{2, s}<\ldots<x_{n, s} \leq x_{n+j, s}$ and fit the model $y_{i, s}=\beta_{i, j, n+j}+\alpha_{n+j} x_{i, s}+e_{i n+j}$. Calculate the mean square error $m s e_{n+j}$.
- $\quad$ Plot the $m s e_{n+j}$ versus $j$. Find the change point that causes $m s e_{n+j}$ to change from a decreasing trend or constant trend to an increasing trend. The rainfall at the change point is taken as the start of an overflow point. This value is $3.8 \mathrm{~mm}$ in Fig. (3).

This suggests that we should not accept any rainfall event with more than $3.8 \mathrm{~mm}$ in the first 15 minutes of the event. This process is repeated for accumulative rainfall over 15 minute intervals.

The rules for defining rainfall events without overflows are as follows:

1. The starting 15-minute interval of rainfall must be below $3.8 \mathrm{~mm}$.

2. The first 30 minutes of the rainfall event must have less than $7.5 \mathrm{~mm}$ of rainfall.

3. The first hour of the total rainfall event must have less than $11 \mathrm{~mm}$ of rainfall.

4. The two hours of the rainfall event must have less than $14 \mathrm{~mm}$ of rainfall.

5. The three hours of the rainfall event must have less than $15 \mathrm{~mm}$.

6. The four hours of the rainfall event must have less than $16 \mathrm{~mm}$.

7. The nine hours of the rainfall event must have less than $28 \mathrm{~mm}$.

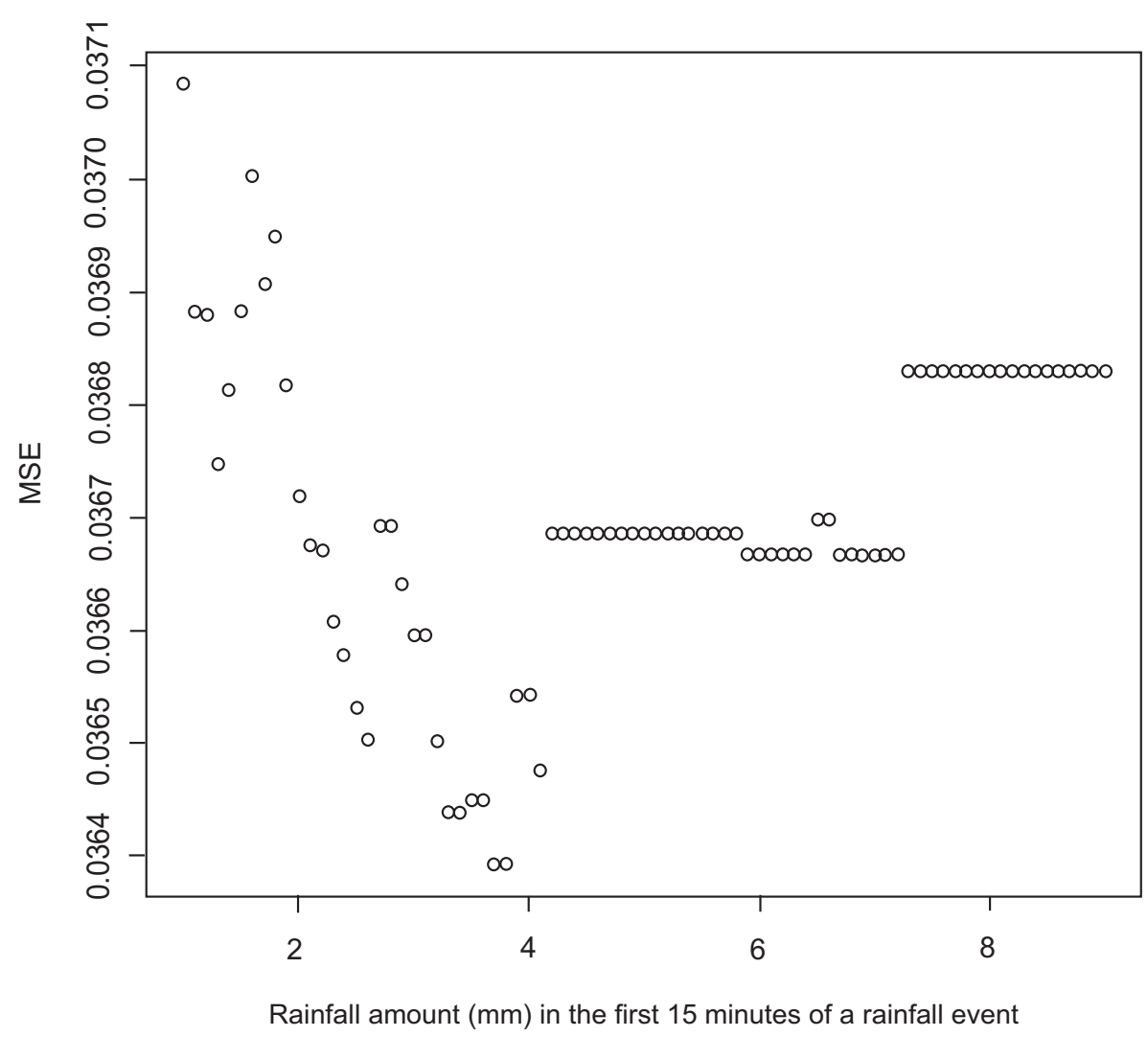

Fig. (3). Flow change point for rainfall amounts in the first 15 minutes of rainfall events. 
We were able to find several rainfall events of different magnitudes that satisfied these rules, and these were used to monitor seepage over the same event for every year of the monitoring period. Six rainfall events that met these specifications were established from the data.

\subsection{Fitting Hydrological/Empirical Models to the Meas- ured Flows}

The hydrological models provided by Sydney Water were MOUSE models. MOUSE models [8] are physicalbased hydrological (semi-deterministic) models that use rainfall as an input to fit level, velocity and flows at certain gauge points in the sewer. The model parameters are catchment runoff constants that depend on the changing catchment characteristics, pipe friction constants, and several other parameters that can be manipulated to fit the measured data. Some of these are auto-calibrated (e.g. manning number for overland flows), while others involve manual calibration (e.g. manning number for channel flows). These models preserve the water balance of flows and therefore are spatiotemporal consistent. These hydrological models explained $80 \%$ of the variation for level and $78 \%$ of the variation for flows. Since the measurement uncertainty was approximately $10 \%$, these models were efficient.

Unfortunately, the calibrated knowledge-based models were not available for the full period. We could have corrected for small but significant biases using an empirical model with the residuals of these hydrological models as the response variable. Note that models were assumed to be unbiased if, and only if, the differences between gauge measurement and model fits were independent of rainfall amount, time-of-the-day, size of flows, day-of-the-year and day-ofthe-week. The empirical models on the other hand explained $83 \%$ of the variation in flows and were unbiased in the sense described in the previous sentence.

There are three sources of errors in predictions. The first is model error. This is controlled by using the MOUSE software. The second is incorrect measurement of the flows, because the model is calibrated in a way that assumes these measurements are correct. The third is incorrect measurement of inputs to the models such as rainfall, pipe dimensions, etc. Rainfall is measured at four locations in the Castle Hill catchment and rainfall elsewhere is not recorded. Despite these facts the final fitted models are surprisingly efficient - typically explaining from $75 \%$ to $90 \%$ of the variation in the measurements. Further information on evaluating the goodness of fit of models is available in [9] and [10]. The model's ability to explain this amount of variation is exceptional given the level of measurement error is expected to be $10 \%$. Despite this performance, the model-fitting process concentrates on fitting high rainfall events accurately and therefore may not be accurate at predicting, say, low dry weather flows. It is necessary, therefore, to check whether these models deliver biased predictions for dry weather flows (see Section 2.3 below).

\subsubsection{Proposed Solutions to Biases in the Hydrological Models}

Each year, Sydney Water spends millions of dollars calibrating and checking their gauges and in turn calibrating the hydrological models using these measurements. These models fit level, velocity and flow throughout the sewerage system. Every year each gauge is checked twice for accuracy, and it is recalibrated if the gauge is assumed to be biased.

As noted above, hydrological models were fitted to these measurements for each year separately, but these were unavailable for all years considered and when they existed produced biased predictions. Although statistically significant, these biases are relatively small when compared to the magnitude of measurements, which range from 0.010 to 0.414 $\mathrm{m}^{3} / \mathrm{sec}$ with a mean of $0.025 \mathrm{~m}^{3} / \mathrm{sec}$. Since fully calibrated hydrological models were not available for the complete study period, empirical models were fitted using the following explanatory variables:

- Year

- An indicator variable for working day $(w d)$ (Saturdays, Sundays and public holidays coded zero and working days one).

- Time-of-the-day in hours (hour) - harmonic, penalised splines and polynomial were tried but polynomials of order 16 proved a better explanatory variable using AIC [12] to select between these.

- Time in days from the start (day) - the usual cosine and sin harmonic proved best and a linear trend in time.

- Rainfall: The following steps are used to define rainfallrelated explanatory variables -

a. Rainfall is aggregated over neighbouring 15 minute intervals - find the aggregation which best correlates with flows - this was aggregation of rainfall over the period with a 30 minute to 1 hour and 45 minutes delay.

b. After correcting for the best aggregation period found in Step a, find the next best aggregation from remaining potential aggregations.

c. Repeat Step b until no significant aggregations are found.

This process gave several aggregations up to and including the prior 4 days of rainfall. The only variables not included in the significant aggregations were current rainfall and rainfall for the period 15 minutes earlier than when flow was measured (i.e., it takes at least 15 minutes from the start of rain before infiltration influences the flows in the sewer).

- The year indicator variable interactions with rainfall aggregations, and wd (weekend indicator variable) interacts with polynomial hour explanatory variable.

Flows were modelled using the log-normal distribution. This model explained $83 \%$ of the variability in the flows. Similarly temporal changes in variance of the residual error of the model were fitted by a reduced subset of these 
explanatory variables using the gamlss package [13-15] in the R Software [16] (the exact form of these models can be obtained from the led author on request). There were no obvious biases in the model in terms of temporal trends in the residuals for either rainfall values, within a day, across days or with size of the flows.

\subsection{Using the Models to Estimate Dry Weather Flows, Wet Weather Flows and Hence Total seepage for the Rainfall Event}

The fitted model was used to estimate flows for rainfall events and the corresponding dry weather flows for the same event duration. Corresponding estimates of seepage were thus estimated by the respective difference in the wet weather and dry weather flows. These estimates of 15minute seepage values were then aggregated over the duration of the event. This was then repeated for the same period for each year during the study period with the appropriate adjustment made to the explanatory variables for each year, but keeping the hour-of-the-day (hour), wd and rainfall aggregation unchanged. The next section examines how these annual seepage estimates for the same rainfall event can be monitored to assess the deterioration in the sewer system.

\subsection{Detecting Significant Increases in Sewer Deteriora- tion}

The goal of this part of the process is to detect significant increases in infiltration early so that timely maintenance can be facilitated before damage to the sewer escalates. We use statistical process control methods to offer this early warning. The control variable is the estimated total infiltration volume for a rainfall event at the same date, time and day-ofthe-week for each year of the evaluation period. The design of control charts for non-homogeneous processes requires the definition of the control variable, its target value and an estimate of the process variance in the control variable.

At this point we have a wet weather model that can interpolate the same rainfall event for identical times of the year (same season, days-of-the-week and times-of-the-day). In addition, we have a dry weather model that can be used to find the expected dry weather flows during wet weather events for each matched period across all years in the study period. The respective differences between the fitted flow values using the dry weather and wet weather models provide the estimated seepage for the matched event across all years. In addition, these models provide the standard errors for the fitted values.

Let $\sigma_{s, t}{ }^{2}$ be the variances of the differences between wet and dry weather estimates of flows at each 15 minute interval $t$. The sum of seepage values overall of all 15-minute time periods in the rainfall event provides an estimate of the total seepage for the event. The variance of the total seepage caused by summing over auto-correlated seepage 15-minute estimates needs to be established. Seepage estimates follow approximately an autoregressive model of order one (i.e. AR (1) process [17]). Let the lag one auto-correlation be denoted by $\rho$ then the variance of total seepage for the rainfall event is given by (let the number of 15-minute intervals to the start of the event be $t=t$ s and the number of 15-minute intervals to the end be $t=t e$ )

$\begin{aligned} & \operatorname{tr}\left[\begin{array}{cccc}\sigma_{S, t s} & 0 & \ldots & 0 \\ 0 & \sigma_{S, t s+1} & \cdots & 0 \\ \cdot & \cdot & \ldots & \cdot \\ 0 & 0 & \ldots & \sigma_{S, t e}\end{array}\right]\left[\begin{array}{cccc}1 & \rho & \ldots & \rho^{t e-t s} \\ \rho & 1 & \ldots & \rho^{t e-t s-1} \\ \cdot & \cdot & \ldots & \cdot \\ \rho^{t e-t s} & \rho^{t e-t s-1} & \ldots & 1\end{array}\right]\left[\begin{array}{cccc}\sigma_{S, t s} & 0 & \ldots & 0 \\ 0 & \sigma_{S, t s+1} & \ldots & 0 \\ \cdot & \cdot & \ldots & . \\ 0 & 0 & \ldots & \sigma_{S, t e}\end{array}\right] \\ = & \sum_{i=t s}^{t e} \sum_{j=t s}^{t e} \sigma_{S, i} \sigma_{S, j} \rho^{|i-j|}\end{aligned}$

where $t r$ represents the trace of the matrix. Note that the correlation matrix is assumed to be constant over all years while the variances are assumed to change from year to year. Therefore, for year $\tau$ the standard deviation for the total seepage of a rainfall event is given by

$\hat{\sigma}_{\text {seepage }, \tau}=\sqrt{\sum_{i=t s}^{t e} \sum_{j=t s}^{t e} \sigma_{S, i} \sigma_{S, j} \rho^{|i-j|}}$

The plot of seepage values for the event across years including the lines plus and minus two standard deviations either side of the seepage estimates will provide the users with a good visual image of system deterioration and its level of significance. The Cumulative Sum (CUSUM) chart of departures in seepage estimated value $S_{\tau}$ from $S_{0}$ (the target value) for the $t$ th year can be used to establish whether this seepage has significantly deteriorated over the years by calculating

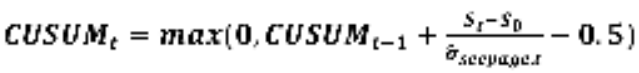

where $S_{0}$ is the seepage value at the start of the study period. An alternative is to allow $S_{0}$ to drift according to an acceptable deterioration rate, and then alarm maintenance managers when this deterioration is unacceptably high. A significant deterioration caused by an increasing level of seepage compared to target value is flagged whenever

CUSUM $_{t}>h$

where the value of $h$ is designed to give a specified false alarm rate specified by the asset manager (e.g. Sydney Water) or an Average Time between false alarms equal to say 50 (this would be on average one false alarm in every $\mathbf{5 0}$ years). After appropriate maintenance is carried out the manager can check for improvement in seepage by simultaneously looking at statistic [18]

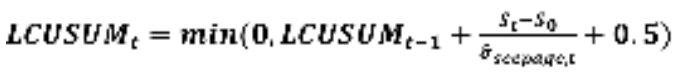

A significant improvement would be indicated whenever

$\operatorname{LCUSU} M_{t}<-h$

These data could be monitored each year for catchments that showed signs of significant deterioration. The value of $h$ for a false alarm rate (flagging significant deterioration when there is none) of one every 100 years can be found using the spc-library [19] in R [16] CUSUM statistics with a resetting boundary manage the memory of past data quite efficiently.

\subsubsection{Results}

The catchment in focus, namely Castle Hill in Sydney, is a stand-alone catchment similar to a boundary catchment. This is the easiest situation to deal with, because we do not 
need to account for flows coming in from a connecting catchment. Six different rainfall events were used to assess the impact of event size on inference.

Fig. (4) provides the seepage estimates for Event 2 together with the autocorrelations and partial autocorrelations of these estimates. To decide when seepage had stopped for the rainfall event, we ran the Exponentially Weighted Moving Average statistic backwards in time for the events and recorded the average time period (rounded) where the seepage started to trend above zero across all years. This recorded value was taken as the end point of the event for all years. The autocorrelation of the seepage values were examined for all events by exploring the autocorrelation and partial autocorrelation functions. All events besides possibly Event 2 indicated that the AR1 model is a reasonable model for this time series.

\subsubsection{Assessing Whether the Trends in Seepage Rates Were Significant}

The estimated total seepage for a rainfall event is one year apart, and under the assumption that there is no change in seepage these estimates should be randomly distributed about the same mean value. Therefore the classical CUSUM and EWMA charts would apply. As the Castle Hill system is relatively new and only small deterioration is anticipated, we would expect the CUSUM charts to be preferred to Shewhart charts [20].

Fig. (A1) in APPENDIX A presents the time series plots of the seepage estimates for all 6 events. Note that the only event that may suggest a hint of deterioration is Event 1. All other events report a reduction in seepage from 2003 to 2005 followed by an increase.

Event 2

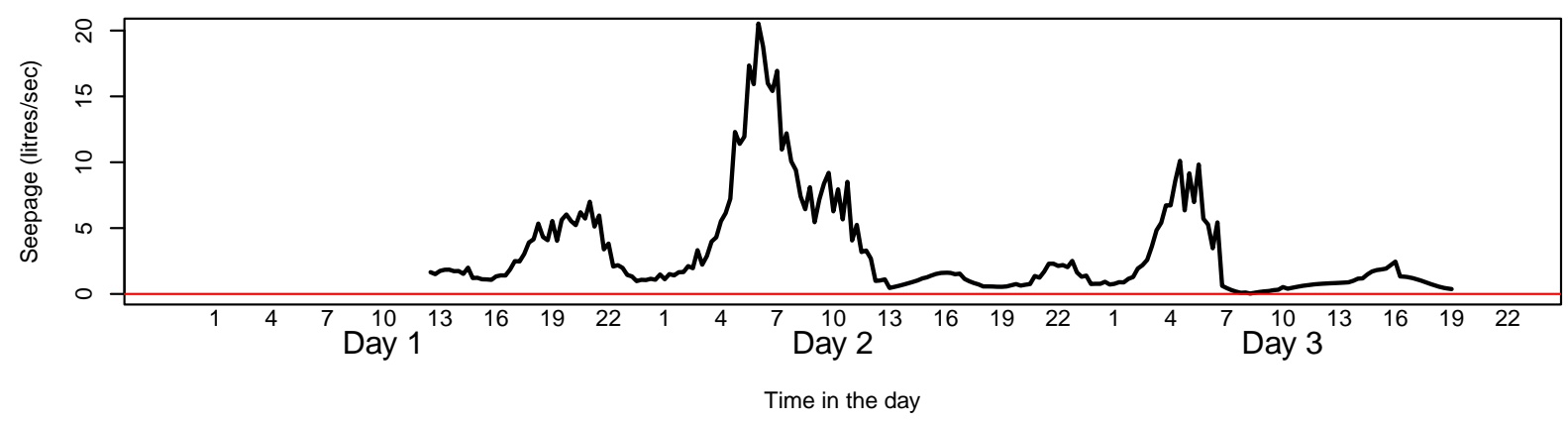

Series seepage

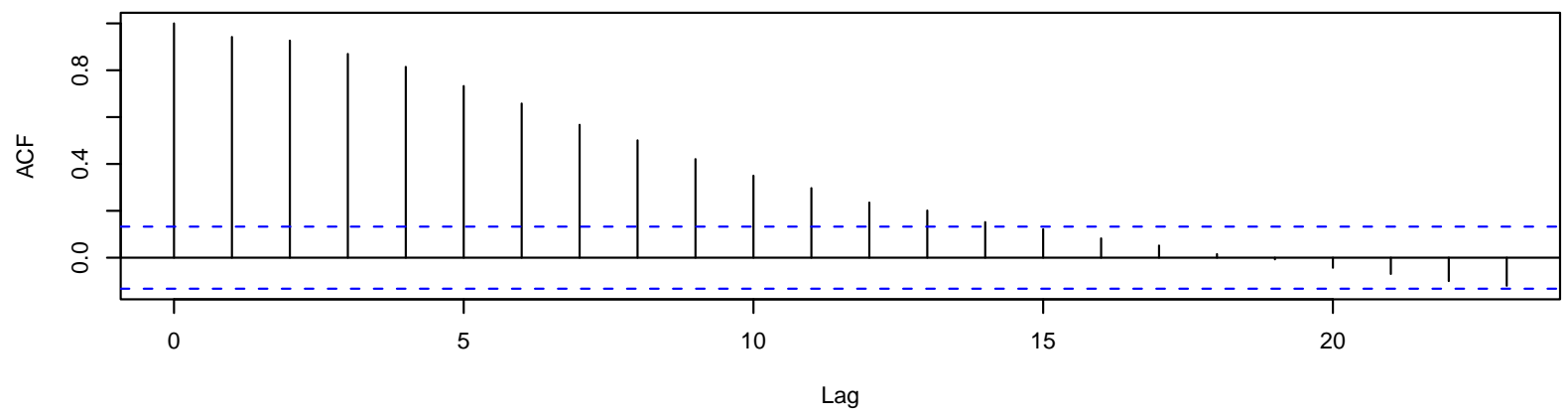

Series seepage

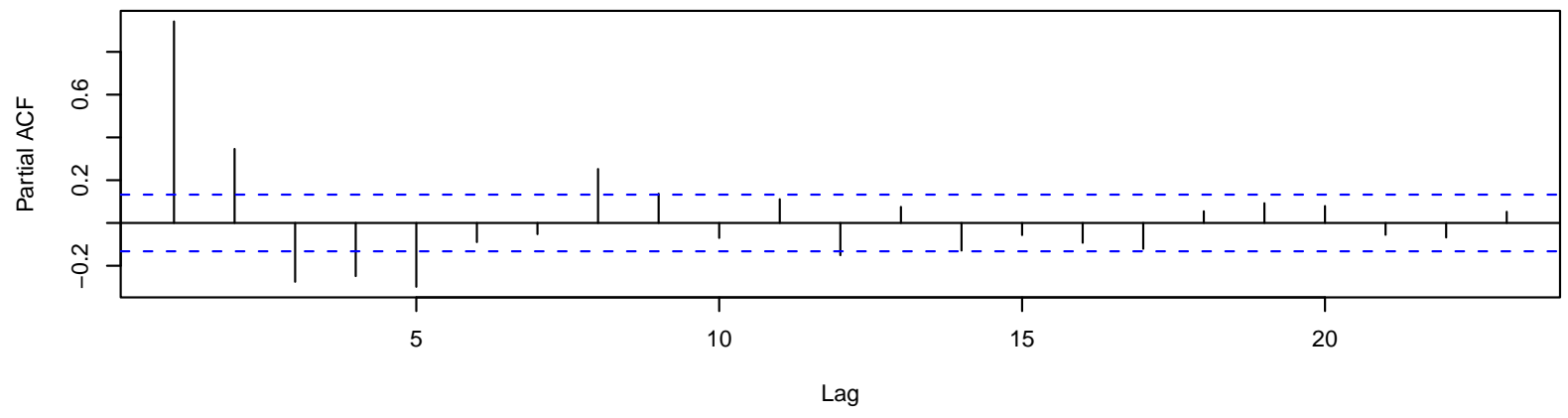

Fig. (4). Time series of seepage estimates for the year of the event and their autocorrelations. 

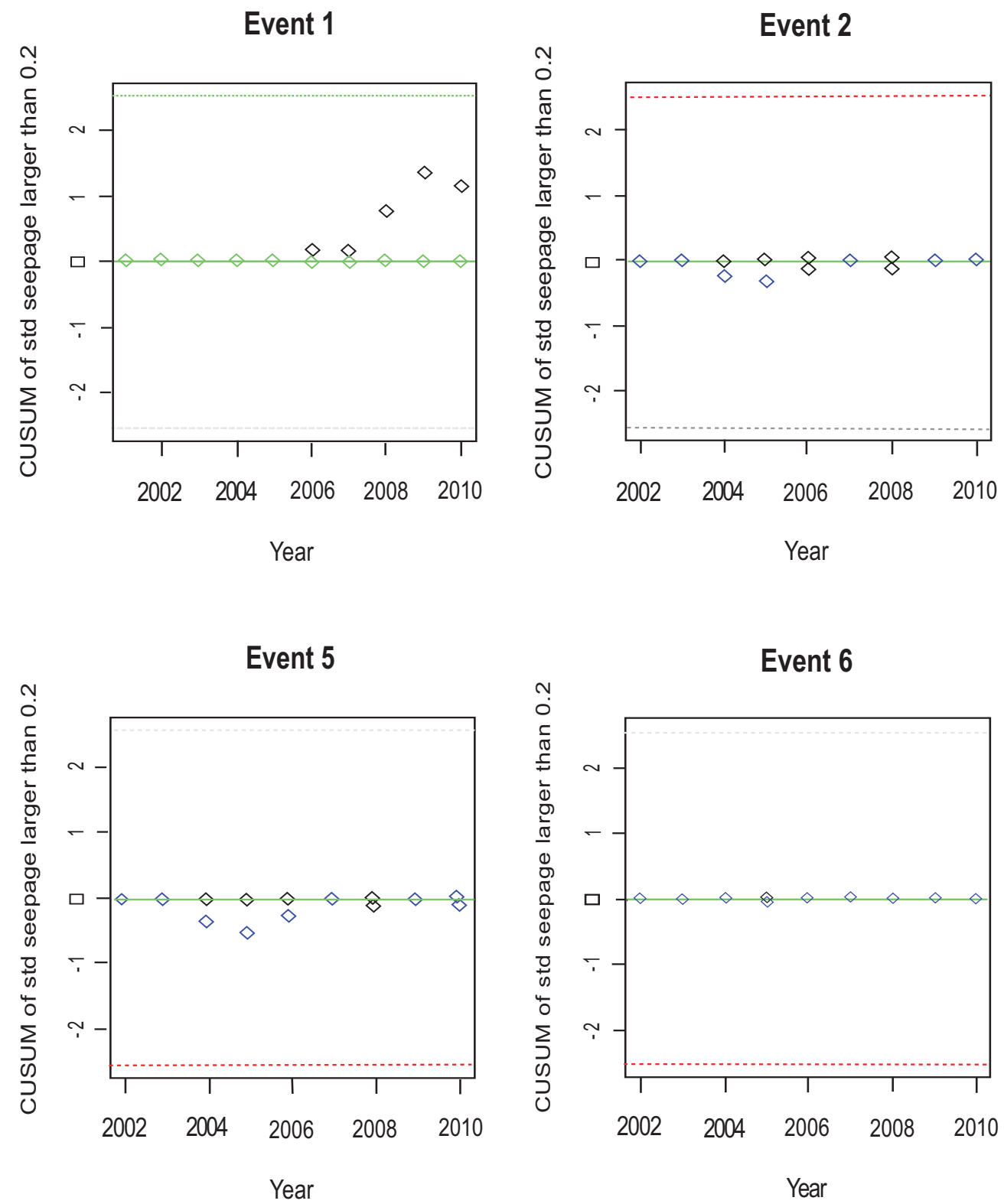

Fig. (5). Low-sided and High-sided CUSUM chart for seepage values.

The CUSUM charts are reported in Fig. (5) for Event 1, 2, 5 and 6 with CUSUM values not all equal to zero. This checks whether seepage has trends from the starting value. The CUSUM plot in Fig. (4) assumes an in-control ARL of 24 (i.e. one false alarm every 24 years) and an offset value $\mathrm{k}=0.2$. The CUSUM chart suggests there has been no significant deterioration in the Castle Hill sewer system.

\section{CONCLUSION}

The paper offers a case study in the application of a process for assessing deterioration in a catchment sewer. The sewer examined was a fairly new sewer and therefore was not expected to show much deterioration. It was selected because it was in a stand-alone catchment with wellcalibrated gauges.
The technology has several elements to its design that are worth investigating. Some of these are listed below:

- Study how differences in the distribution of rainfall event for year to year influence inference (i.e. chart sensitivity).

- Study how knowledge-based hydrological models and empirical-based models can be integrated to provide a better estimate of seepage during a rainfall event.

- Study the method for selecting overflow events. This is likely to lead to events closer to the average dry weather flow of 92 litres/sec and thus improve the ability to signal trends in seepage overtime.

- Assess whether the dry weather flow simulator developed for this project has application in hydrologicalbased models. 
- Test the methodology on other catchments to see if seepage trends can be detected.

- $\quad$ See if the methodology can be used to monitor for statistical significance changes in overflow events from year to year (both volume and number).

This future work is likely to help refine the approach outlined in the paper into a useful asset management tool for assessing deterioration in sewers.

\section{CONFLICT OF INTEREST}

The authors confirm that this article content has no conflicts of interest.

\section{ACKNOWLEDGEMENTS}

The authors would like to thank Rob McGregor of InfoCLEAR Consulting for suggestions on improving the presentation of this paper.

\section{APPENDIX A}

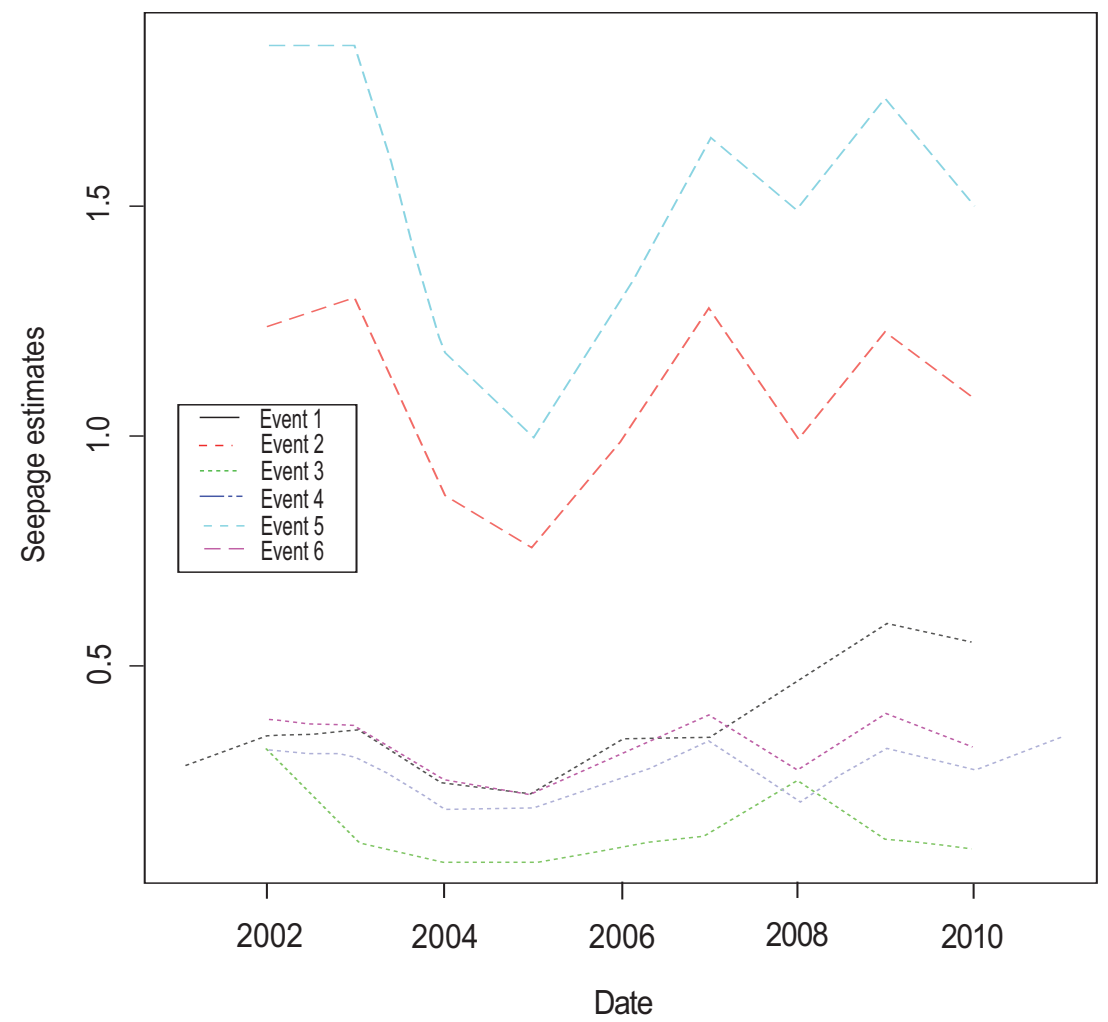

Fig. (A1). Time series plot of seepage total estimates (in $\mathrm{m}^{2} / \mathrm{sec}$ times the duration of the event) for the 6 events.

\section{REFERENCES}

[1] J. B. Ellis, "Infiltration Systems: A Sustainable Source-Control Option for Urban Stormwater Quality Management”. J. Chart. Inst. Wat. Environ. Manag., vol. 14, , pp. 27-34, 2000

2] M. Rutsch. "Assessment of sewer leakage by means of exfiltration measurements and modelling tests”, Unpublished Doctorate Dissertation at Dresden University of Technology. 2006.

[3] C. Karpf and P. Krebs, "Application of the leakage model to assess exfiltration”. In: Proceedings of Int. Conference on Urban Drainage Modelling, Dresden. 2004, pp. 217 - 24.

[4] R. Wirahadikusumah, D. Abraham and T. Iseley, "Challenging issues in modelling deterioration of combined sewers", J Infrastruct. Syst., vol. 7, no. 2, pp. 77-84.

[5] J. P. Davies, B. A. Clarke, J. T Whiter and R. J. Cunningham, "Factors influencing the structural deterioration and collapse of rigid sewer pipes”. Urban Water, vol. 3, pp. 77-89, 2001

[6] T. J. Lutz, "Comparing Inflow and Infiltration". Water Sewage Works, , pp. 65 - 69, May 1976.

[7] S. Tsitsifli, V. Kanakoudis, and I. Bakouros, "Pipe networks risk assessment based on survival analysis". Water Resources Management, vol. 25, no. 14, 2011, pp. 3729-3746.
[8] DHI Modeling of Urban Sewers (MOUSE) "Users manual and tutorial” (Version 2000), DHI, Horsholm, Denmark.

[9] M.B.Butts, J.T. Payne, M. Kristensen and Madsen, H. “An evaluation of the impact of model structure on hydrological modelling uncertainty for streamflow simulation”, J. Hydrol. vol. 288, no. 2004, pp. 242-266.

[10] Z. Zhang, S. Wang, G. Sun, S.G. McNulty, H. Zhang, J. Li, M. Zhang, E. Klaghofer and P. Strauss "Evaluation of the MIKE SHE model for application in the Loess Plateau, China”, J. Am. Water Res. Assoc., vol. 44, no. 2008, pp. 1108-1120

[11] Z. Harchaoui and C. Levy-Leduc, "Multiple change-point estimation with a total variation penalty". J. Am. Stat. Assoc., vol. 105, no. 2010, pp. 1480-1493.

[12] H. Akaike, "A new look at the statistical model identification”. IEEE Trans. Auto. Cont., vol. 19, no.6, 1974, pp. 716-723.

[13] R. A. Rigby and D. M. Stasinopoulos "Generalized additive models for location, scale and shape,(with discussion)”, Appl. Stat., vol. 54, no. 3, pp. 507-554, 2005.

[14] D. M. Stasinopoulos, R. A. Rigby and C. Akantziliotou "Instructions on how to use the GAMLSS package in R". Accompanying documentation in the current GAMLSS help files, 2006 ( available at: http://www.londonmet.ac.uk/gamlss/). 
[15] D. M. Stasinopoulos and R. A. Rigby "Generalized additive models for location scale and shape (GAMLSS) in R”, J. Stat. Software, vol. 23, no. 7, Dec 2007, http://www.jstatsoft.org/v23/i07

[16] R Development Core Team "R: A Language and Environment for Statistical Computing”. R Foundation for Statistical Computing, Vienna, Austria. ISBN 3-900051-07-0, Version 2.6.1, 2007, Available at: http://www.R-project.org/.
[17] G.E.P. Box. and G.M. Jenkins (1970) "Time Series Analysis: Forecasting and Control”, Holden-Day, San Francisco.

[18] E.S. Page "Continuous inspection schemes". Biometrika, vol. 41, pp. 100-114, 1954

[19] S. Knoth “spc: Statistical Process Control”, R package version 0.1, 2004.

[20] D.C. Montgomery, "Introduction to Statistical Quality Control", $6^{\text {th }}$ Ed., John Wiley and Sons, Inc., NY., 2009.

Received: August 06, 2013

Revised: September 17, 2013

Accepted: September 27, 2013

(C) Sparks and Kasmarik; Licensee Bentham Open.

This is an open access article licensed under the terms of the Creative Commons Attribution Non-Commercial License (http://creativecommons.org/licenses/ by-nc/3.0/) which permits unrestricted, non-commercial use, distribution and reproduction in any medium, provided the work is properly cited. 